\title{
Study of the Dependence of the Air Flow Velocity on the Parameters of the Suction Nozzle Installation of the Peat Pneumatic Harvesting Machine
}

\author{
Alexander Yablonev ${ }^{1, *}$, Oleg Misnikov ${ }^{1}$, Darya Scherbakova ${ }^{1}$, and Valentin Goryachev ${ }^{1}$ \\ ${ }^{1}$ Tver State Technical University (TvSTU), 170026, Afanasy Nikitin emb., 22, Tver, Russia
}

\begin{abstract}
The parameters influencing the suction efficiency of peat pneumatic harvesters are listed. Among them are the distance from the nozzle to the underlying surface and the angle of the nozzle. Since there is very little information and recommendations on the rational values of these parameters, it was decided, using a specially designed installation, to conduct a laboratory experiment to assess the air flow velocity, depending on the distance from the nozzle, the angle of the nozzle and the height of the nozzle above the underlying surface of the deposit. The results of the experiment are presented. It is shown, that the rational angle of the nozzle at this stage of research can be considered an angle of $30 \pm 5^{\circ}$. In practice, it is impossible to reproduce the zero distance from the nozzle to the underlying surface; therefore, it is recommended to limit the height of $25 \mathrm{~mm}$, which is equal to the maximum size of the conditioned peat crumb. It is noted, that for more accurate results, it is necessary to carry out the following series of experimental works to assess the parameters of suction of peat chips with specific physical and mechanical characteristics.
\end{abstract}

\section{Introduction}

Peat extraction by pneumatic harvesting machines has a number of indisputable advantages over mechanical harvesting. Among them - a reduction in the duration of the cycle and the range of equipment, the possibility of preserving the natural fibrous structure of peat, which is necessary for the production of fertilizers $[1,2]$. The intensification of the extraction of milled peat by pneumatic harvesters largely depends on their reliability, the correct choice of settings and the installation of the suction nozzle [3]. It is the angle of the nozzle in combination with the height of its location above the underlying surface, that determines the length and intensity of the suction plume. It is quite obvious, that in order to reduce the energy losses of the air stream and peat during harvesting, the height of the nozzle above the underlying surface should be as small, as possible, and be within the range of $0-25 \mathrm{~mm}$, that is, it should not exceed the size of the largest fraction of the conditioned peat being mined. At the same time, the nozzle in no case should exert vertical pressure on the spread, since,

\footnotetext{
*Corresponding author: alvovich@mail.ru
} 
otherwise, the effects of pressing and mixing of the spread appear $[4,5]$. To date, there are no precise data and recommendations on the choice of the nozzle angle, except for the provision that it cannot exceed the angle of internal friction of the rock being mined (L. O. Gortsakalian, 1973). This provision is based on the idea, that milled peat, that has got into the nozzle under the action of an air jet, should not spontaneously roll down [6]. For milled peat, the angle of repose (friction at rest) is $32-45^{\circ}$. Since the angle of internal friction of bulk material in motion is, as a rule, $70 \%$ of the angle of internal friction at rest, the recommended angle of installation of the nozzle is $22.4-31.5^{\circ}$. Premier Tech's SA-200 Canadian peat harvesters are available with vertically mounted nozzles (nozzle angle close to $90^{\circ}$ ). However, the experience of operating such machines has shown, that vertical nozzles do not fit well into the surface relief of peat fields and form large losses of peat during collection (L. R. Davidov, V. G. Selennov, 2008), although they allow increasing the width of the nozzle and, accordingly, the width of the machine [7, 8]. The spread of the parameters of the nozzle setting is, as can be seen, very large. Therefore, it was decided to conduct a series of laboratory experimental works, the purpose of which is to determine the speed of the air flow sucked in by the nozzle, depending on the angle of the nozzle and the height of its location above the underlying surface of the deposit.

\section{Method Used}

The developed and created experimental laboratory installation for determining the speeds and parameters of the suction and hovering of peat chips consists of a direct current (DC) source 1 , a direct current motor 2 , a fan 3 , a straightening grate 4 , a winding tube 5 , a winding tube frame 6 , a control panel 7, a micromanometer 8 , a corrugated aluminum tube 9 , a rack 10 , an experimental nozzle 11, a conveyor belt, made of a 2-layer rubberized tarpaulin 12 , stands 13 and a frame of the setup 14 (Figure 1).

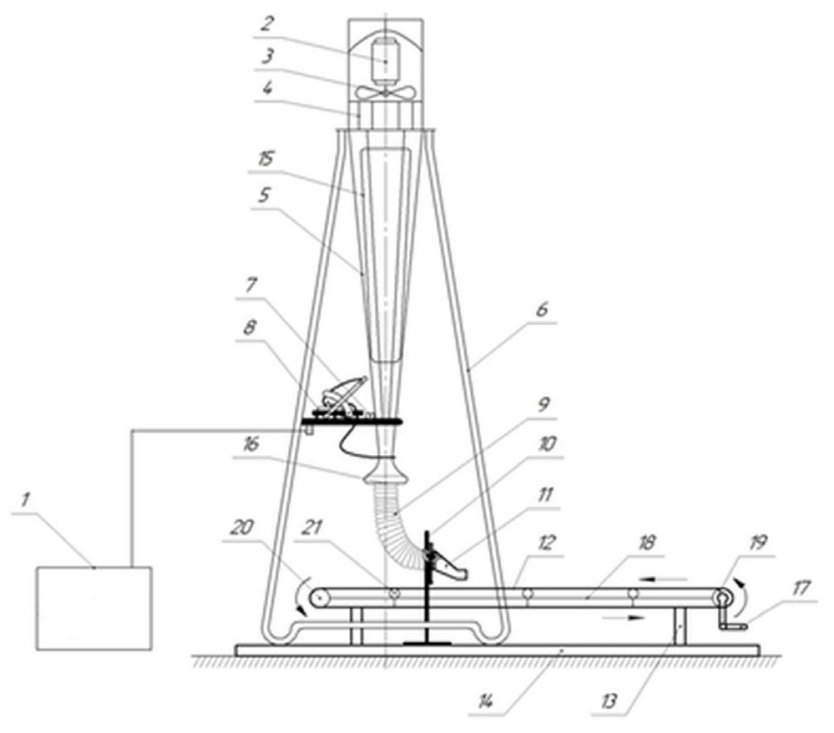

Fig. 1. General view of the experimental setup.

From the DC source 1 through the control panel 7, voltage is supplied to the motor 2, which drives the fan impeller 3. Simultaneously, the control panel 7 turns on the vertical illumination 15. A straightening grille 4 is installed in front of the fan 3 , which is necessary to stabilize the movement of the air mixture through the winding tube 5 . A micromanometer 
8 is connected to the collector 16 of the winding pipe 5 to measure the vacuum pressure in the collector 16 of the pipe. Through the experimental nozzle 11, connected to the collector of the winding pipe 5 by a corrugated aluminum pipe 9 , peat chips with a fraction of $d=0$ $40 \mathrm{~mm}$ can be sucked in, moving along the conveyor belt 12 . The conveyor belt 12 is mechanically driven by means of the drive handle 17 towards the experimental nozzle 11 . The conveyor is represented by racks 13 , rigidly fixed to the frame of the installation 14, the frame of the conveyor belt 18 , the driving 19 and the tensioning 20 of the driven drums, and supporting rollers 21 .

Figure 2 (A-A) shows the connection of the micromanometer to the collector 16 of the winding tube $5(\mathrm{~A}-\mathrm{A})$ and the relative position of the installation locations of the control panel 7 , the rheostat for regulating constant voltage 22 and the micromanometer 8 (B-B). Micromanometer 8 is connected to the manifold 16 of the winding pipe 5 by means of a flexible hose 24 attached to the fitting 25 of the annular pipeline 26 installed around the manifold 16 and connected to it by orthogonally located four nozzles 27 necessary to equalize the pressure readings.
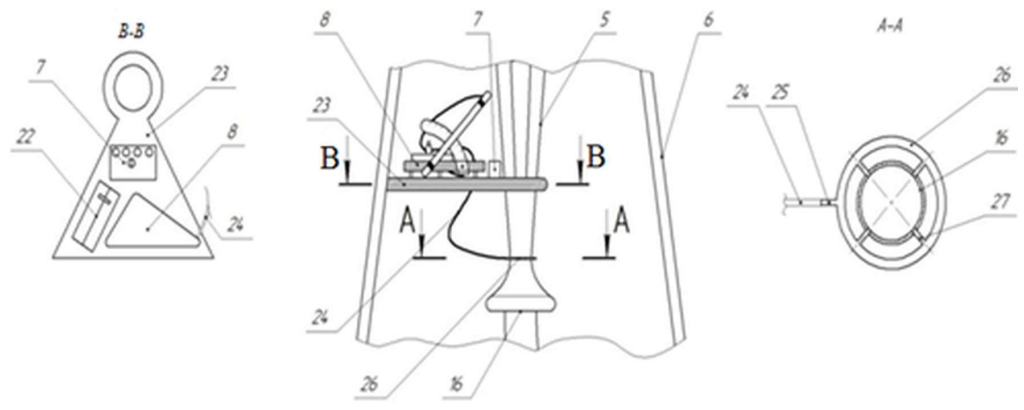

Fig. 2. The layout of the control devices.

Figure 3 shows the attachment of the experimental nozzle 11 to the rack 10 . The nozzle and the aluminum corrugated pipe 9 are interconnected by a coupling 28, which is fixed on a movable rod 29 and allows you to adjust the angle of inclination of the nozzle and the distance between the nozzle and the surface of the conveyor belt 12 . To measure the angle of inclination the nozzle is equipped with a goniometric scale 30 and an arrow with a weight of 31. The nozzle can be rotated at an angle of $0-90^{\circ}$ and rise above the conveyor belt by a distance of $0-400 \mathrm{~mm}$.

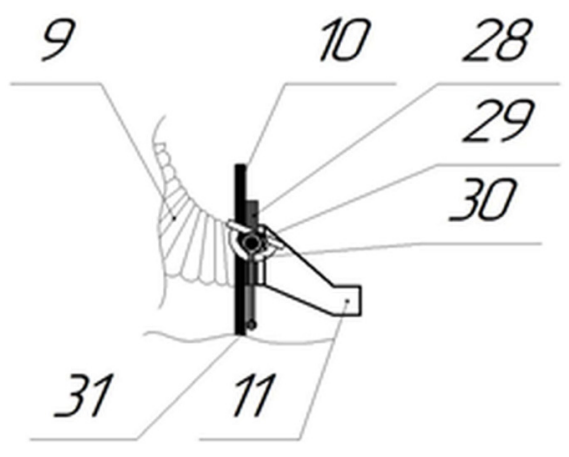

Fig. 3. Suction nozzle attachment. 
To measure the air flow velocity at various distances from the lower edge of the suction nozzle, an external probe of a portable digital thermal anemometer GM8903 is placed on the grid (Figure 4) [9].

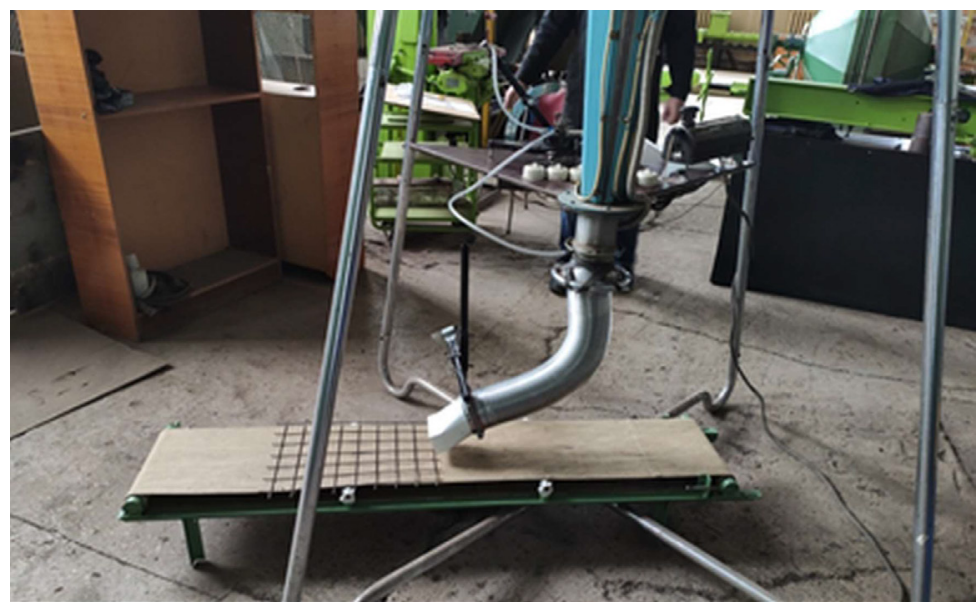

Fig. 4. Coordinate grid on the conveyor belt.

The air flow velocities at different points of the suction plume were recorded at an air flow rate at the nozzle inlet of $26.69 \mathrm{~m} / \mathrm{s}$, corresponding to the speed at the nozzle inlet of a real Estonian peat harvesting KTT-2 machine [9]. The distance from the conveyor to the lower edge of the nozzle was taken as 0 and $25 \mathrm{~mm}$. The nozzle angle during a series of experiments was varied from 10 to $45^{\circ}$ with a step of $5^{\circ}$.

\section{Results and discussion}

As a result of processing a series of experimental data, two groups of curves were obtained, which are the dependences of the air flow velocity $v_{x}$ on the distance from the nozzle $x$, the angle of the nozzle $\alpha$ and the height $h$ of the nozzle location above the surface of the conveyor belt 0 and $25 \mathrm{~mm}$, shown in Figures 5 and 6.

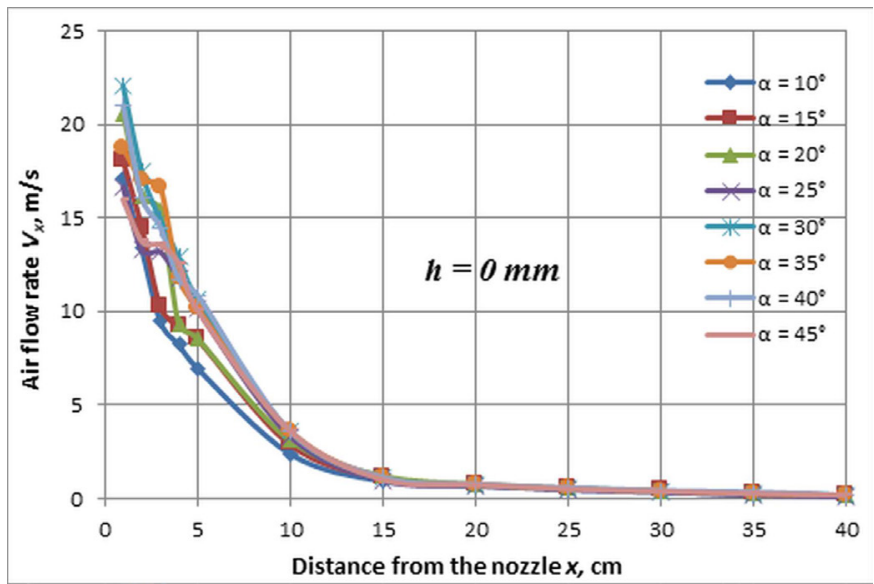

Fig. 5. Dependence of the air flow velocity $v_{x}$ on the distance from the nozzle $x$ at different angles of the nozzle installation $\alpha$ and the distance from the nozzle to the underlying surface $h=0 \mathrm{~mm}$. 


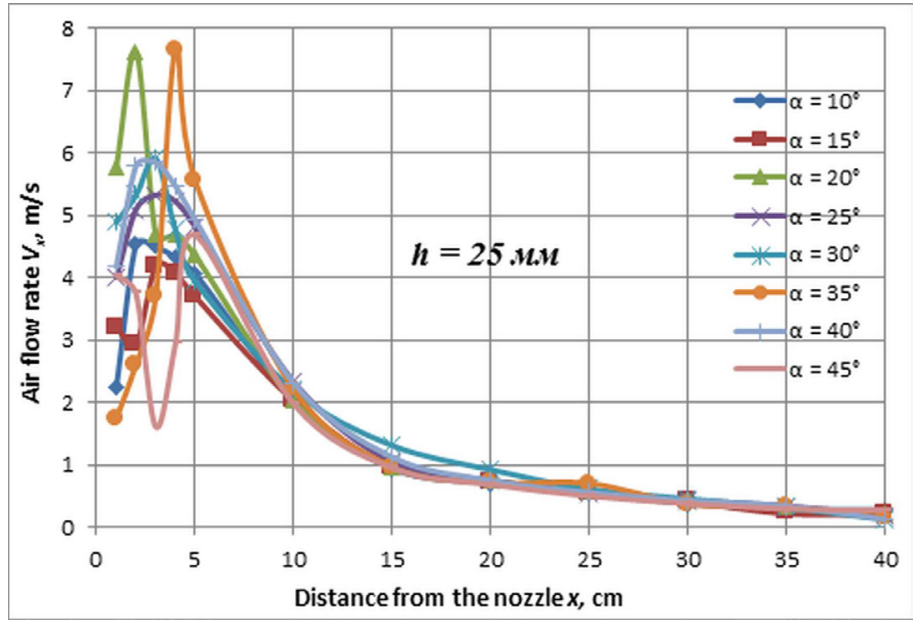

Fig. 6. Dependence of the air flow velocity $v_{x}$ on the distance from the nozzle $x$ at different angles of the nozzle installation $\alpha$ and the distance from the nozzle to the underlying surface $h=25 \mathrm{~mm}$.

\section{Conclusion}

Based on the analysis results in Figure 5, the following can be noted. At a distance of $10 \mathrm{~cm}$ from the lower edge of the nozzle, the air flow velocity decreases 4.5-7 times compared to the speed at a distance of $1 \mathrm{~cm}$. An air flow velocity of less than $1 \mathrm{~m} / \mathrm{s}$ is observed in all cases at a distance of $20 \mathrm{~cm}$ from the nozzle. When the measuring point is removed from the nozzle at a distance of more than $15 \mathrm{~cm}$, the dependence of the speed on the distance, due to minor fluctuations, can be considered linear. The absence of characteristic "peaks" in almost all cases indicates a weak turbulence of the air flow. An insignificant manifestation of turbulence is manifested by small disturbances on the curves with $\alpha=15-45^{\circ}$. The highest value of the air flow velocity at a distance of $1 \mathrm{~cm}$ from the lower edge of the nozzle is observed for the nozzle angle $\alpha=30^{\circ}$.

Based on the analysis results in Figure 6, the following can be noted. At a distance of 10 $\mathrm{cm}$ from the lower edge of the nozzle, the air flow speed decreases 1.5-2 times compared to the speed at a distance of $1 \mathrm{~cm}$. The air flow speed less than $1 \mathrm{~m} / \mathrm{s}$ is observed in the overwhelming majority of cases at a distance of $20 \mathrm{~cm}$ from the nozzle. The maximum suction speed is observed at a distance of $2-5 \mathrm{~cm}$ from the lower edge of the nozzle (depending on the angle of the nozzle installation). When the measuring point is removed from the nozzle at a distance of more than $20 \mathrm{~cm}$, the dependence of the speed on the distance can be considered linear due to slight fluctuations. The presence of characteristic "peaks" in all cases indicates a strong turbulence of the air flow. The strongest manifestation of turbulence is manifested by small disturbances on the curves with $\alpha=20-35^{\circ}$. The highest value of the air flow velocity at a distance of $1 \mathrm{~cm}$ from the lower edge of the nozzle is observed for nozzle angles $\alpha=20-45^{\circ}$.

Based on the results of a series of experiments, the following conclusions can be drawn. Since it is practically impossible to ensure a zero distance between the suction nozzle and the peat crumb spreading surface, you should limit yourself to at least $25 \mathrm{~mm}$, which is equal to the maximum size of the conditioned peat crumb. In addition, weak turbulence of the air flow for zero distance above the underlying surface indicates the difficult conditions for creating a lifting force to separate the particle from the underlying surface. The preliminary rational angle of installation of the nozzle on the fact of the value of the air flow rate at this stage of 
the study can be considered $\alpha=30 \pm 5^{\circ}$. For a more accurate experimental substantiation of the rational angle of the nozzle installation, it is necessary to carry out a series of experimental works to assess the suction of peat chips with the given properties of nozzles mounted at angles of $10-45^{\circ}$. Such a study will help to finally formulate the requirements for the parameters of the installation of the suction nozzle, and, consequently, will contribute to more rational management and careful handling of invaluable natural resources, which, no doubt, is peat $[10,11]$.

\section{References}

1. V. V. Panov, O. S. Misnikov, Min. J., 7, 108-112 (2015)

2. R. K. Singh, A. Das, Fuel Processing Technology, 115, 71-78 (2013)

3. E. Chertkova, V. Sizova, E3S Web of Conf. 105, 01002 (2019)

4. J. X. Wang, C. B. Le Doux, C.B., Y,X. Li, Int. J. of Forest Engineering, 16:2, 77-85 (2005)

5. W. Jucha, P. Mareczka, D. Okupny, Mires and Peat, 26, 19 (2020)

6. V. N. Makarov, V. Y. Potapov, S. Y. Davydov, N. V. Makarov, J. Refractories and Industrial Ceramics, 58(3), 288-292 (2017)

7. J. Korpi, Proceed.13-th Int. Peat Cong., Tullamore, Ireland, 1, 120-122 (2008)

8. E. A. Kremcheev, D. A. Kremcheeva, Indian J. of Science and Technology, 9(12), 89525 (2016)

9. A. Yablonev, D. Scherbakova, E3S Web of Conf. 174, 01044 (2020)

10. A. Bonn, T. Allot, M. Evans, H. Joosten, R. Stoneman, Peatland Restoration and Ecosystem Services: Policy and Practice (Cambridge University Press, Cambridge, 2016)

11. R. Lindsay, R. Birnie, IUCNUK Committee Peatland Programme, 6, 1-5 (2014) 